\title{
Synthesis of Homoallylic Alcohols in Aqueous Media using Potassium Allyltrifluroborate
}

\author{
Fernanda C. G. Barbosa*, Caio F. Melo, Paulo H. Menezes, Roberta A. Oliveira \\ Departamento de Química Fundamental, CCEN, UFPE, 50670-901, Recife-PE, Brasil \\ *nandagomes@gmail.com
}

Keywords: potassium allyltrifluoroborate, allylation, homoallylic alcohols

\section{INTRODUCTION}

The addition of crotyl and allylorganometallics to carbonyl compounds is of considerable importance in organic synthesis. However, the utility of many of these organometallics is limited by their susceptibility to air and/or moisture. ${ }^{1}$

Organotrifluoroborates have proven to be a good option to replace boronic acids and boronate esters providing advantages over the latter reagents in many types of reactions. Among various allylmetal reagents, potassium allyltrifluoroborate is preferred given the recent demand for safe and sustainable organic synthesis, because this reagent is airstable. $^{2}$

As part of ongoing studies on the synthesis and reactivity of organotrifluoroborate salts, herein we report the general and convenient 18-C-6 induced allylation of aldehydes by potassium allyltrifluoroborate.

\section{RESULTS AND DISCUSSION}

Initially, the effect of the addition of a catalytic amount of $18-C-6$ in the allylation reaction was tested using the 4-nitro-benzaldehyde as substrate and potassium allyltrifluoroborate using a biphasic reaction medium (Scheme 1).

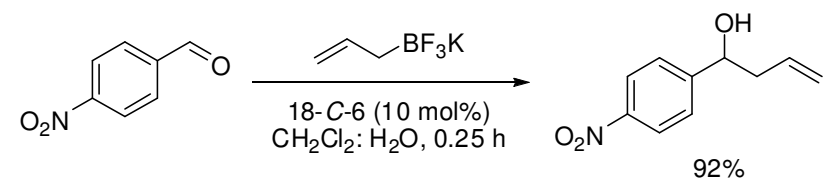

Scheme 1

The corresponding homoallylic alcohol was obtained in good yield without the necessity of further purification. In the absence of $18-C-6 \mathrm{C}$, the reaction was found to be rather sluggish (15\% yield after 15 min at $25^{\circ} \mathrm{C}$ ) and was incomplete after $15 \mathrm{~min}$ if less than $10 \mathrm{~mol} \%$ of $18-\mathrm{C}-6$ was used.

The scope of the transformation was established with a variety of different aldehydes using $18-C-6$ as the PTC. Aliphatic, aromatic, $\alpha, \beta$-unsaturated, and heterocyclic aldehydes were efficiently allylated in good yields. The reaction tolarates nitro group (Table 1, entries 1) and, in the case of acrylaldehyde only 1,2-addition was observed (Table 1 , entry 6 ).
Table 1. Addition of potassium allyltrifluoroborate to different aldehydes promoted by $18-C-6$

$$
\overbrace{\mathrm{O}} \frac{\mathrm{BF}_{3} \mathrm{~K}}{\begin{array}{c}
18-\mathrm{C}-6(10 \mathrm{~mol} \%) \\
\mathrm{CH}_{2} \mathrm{Cl}_{2}: \mathrm{H}_{2} \mathrm{O}, 0.25 \mathrm{~h}
\end{array}}
$$

isolated yield

\section{CONCLUSION}

In summary, we developed a generally green and convenient allylation method to various functionalized aldehydes using potassium allyltrifluoroborate and $18-C-6$. The application of the method in the allylation of other compounds as well as the asymmetric version of the reaction is undergoing in our laboratories.

\section{ACKNOWLEDGEMENTS}

CNPq, CAPES, FACEPE and INCT-INAMI

\section{REFERENCES}

1 (a) Yamamoto, Y.; Asao, N. Chem. Rev. 1993, 93, 2207-2293; (b) Denmark, S. E.; Fu, J. Chem. Rev. 2003, 103, 2763-2793.

${ }^{2}$ Thadani, A. N; Batey, R. A. Org. Lett. 2002, 4, 3827-3830. 